\title{
Does Radiographic Coxa Profunda Indicate Increased Acetabular Coverage or Depth in Hip Dysplasia?
}

\author{
Masanori Fujii MD, PhD, Tetsuro Nakamura MD, \\ Toshihiko Hara MD, Yasuharu Nakashima MD, PhD, \\ Yukihide Iwamoto MD, PhD
}

Received: 4 August 2014/Accepted: 24 November 2014/Published online: 5 December 2014

(C) The Association of Bone and Joint Surgeons (B) 2014

\begin{abstract}
Background Although radiographic coxa profunda has been considered an indicator of acetabular overcoverage, recent studies suggest that radiographic coxa profunda is a nonspecific finding seen even in hip dysplasia. The morphologic features of coxa profunda in hip dysplasia and the frequency with which the two overlap are not well defined. Questions/purposes We determined (1) the prevalence of radiographic coxa profunda in patients with hip dysplasia;
\end{abstract}

Each author certifies that he or she, or a member of his or her immediate family, has no funding or commercial associations (eg, consultancies, stock ownership, equity interest, patent/licensing arrangements, etc) that might pose a conflict of interest in connection with the submitted article.

All ICMJE Conflict of Interest Forms for authors and Clinical Orthopaedics and Related Research ${ }^{\mathbb{R}}$ editors and board members are on file with the publication and can be viewed on request.

Clinical Orthopaedics and Related Research ${ }^{\circledR}$ neither advocates nor endorses the use of any treatment, drug, or device. Readers are encouraged to always seek additional information, including FDA-approval status, of any drug or device prior to clinical use. Each author certifies that his or her institution approved the human protocol for this investigation, that all investigations were conducted in conformity with ethical principles of research, and that informed consent for participation in the study was obtained.

This work was performed at the Department of Orthopaedic Surgery, Japan Community Health Care Organization, Kyushu Hospital, Kitakyushu, Japan.

\section{Fujii $(\bowtie)$, T. Nakamura, T. Hara}

Department of Orthopaedic Surgery, Japan Community Health

Care Organization, Kyushu Hospital, 1-8-1 Kishinoura,

Yahatanishi-ku, Kitakyushu 806-8501, Japan

e-mail: masanorif9@gmail.com

Y. Nakashima, Y. Iwamoto

Department of Orthopaedic Surgery, Graduate School of

Medical Sciences, Kyushu University, Fukuoka, Japan
(2) the morphologic differences of the acetabulum and pelvis between patients with hip dysplasia and control subjects; and (3) the morphologic differences between hip dysplasia with and without coxa profunda.

Methods We retrospectively reviewed the pelvic radiographs and CT scans of 70 patients (70 hips) with hip dysplasia. Forty normal hips were used as controls. Normal hips were defined as those with a lateral center-edge angle between $25^{\circ}$ and $40^{\circ}$. Coxa profunda was defined as present when the acetabular fossa was observed to touch or was medial to the ilioischial line on an AP pelvic radiograph. CT measurements included acetabular version, acetabular coverage, acetabular depth, and rotational alignment of the innominate bone.

Results The prevalence of coxa profunda was $44 \%$ (31 of 70 hips) in dysplastic hips and 73\% (29 of 40 hips) in the control hips (odds ratio, 3.32; 95\% CI, 1.43-7.68). Dysplastic hips had a more anteverted and globally shallow acetabulum with inwardly rotated innominate bone compared with the control hips $(\mathrm{p}<0.001)$. Dysplastic hips with coxa profunda had a more anteverted acetabulum $(\mathrm{p}<0.001)$ and inwardly rotated innominate bone $(\mathrm{p}<0.002)$ compared with those without coxa profunda, whereas the acetabular coverage and depth did not differ between the two groups, with the numbers available.

Conclusions Radiographic coxa profunda was not a sign of increased acetabular coverage and depth in patients with hip dysplasia, but rather indicates classic acetabular dysplasia, defined by an anteverted acetabulum with anterolateral acetabular deficiency and an inwardly rotated pelvis. Thus, the presence of coxa profunda does not indicate a disease in addition to hip dysplasia, and the conventional maneuvers during periacetabular osteotomy are adequate for these patients.

Level of Evidence Level IV, diagnostic study. 


\section{Introduction}

Femoroacetabular impingement (FAI) has been recognized as a mechanical etiology that leads to early osteoarthritis $[5,16]$. Radiographic coxa profunda, defined as present when the acetabular fossa is observed to touch or is medial to the ilioischial line on a standard AP pelvic radiograph (Fig. 1), has been considered a radiographic indicator of global acetabular overcoverage or pincer FAI [5, 8, 16, 28, 30]. However, Boone et al. [6] suggested that coxa profunda is not a specific finding for acetabular overcoverage: they reported that radiographic coxa profunda was poorly specific for global overcoverage with a specificity of $62 \%$. Moreover, several authors have reported that coxa profunda can be seen in asymptomatic normal hips [4] and various hip disorders, including hip dysplasia, regardless of the acetabular coverage [3, 27].

Hip dysplasia is a common cause of hip osteoarthritis [18] and is characterized by insufficient acetabular coverage of the femoral head, shallow acetabular concavity, and joint instability that causes elevated joint contact pressure and searing stress on the acetabular rim complex [17, 19], resulting in early hip degeneration [22, 33]. To our knowledge, no prior studies have looked at coxa profunda in patients with hip dysplasia, and the morphologic features and clinical importance of this deformity have not been characterized. Certain FAI-related deformities such as acetabular retroversion and decreased femoral head-neck offset have been reported to coexist in hip dysplasia and to have an effect on planning and surgical decision-making in hip preservation surgeries for patients $[1,14,15,26]$. It is unclear whether the presence of coxa profunda indicates an additional pathomechanism or has an effect on the treatment strategy for patients with hip dysplasia. Because plain radiographs play a major role in diagnosing the pathologic features of early hip disorders, a comprehensive morphologic analysis regarding coxa profunda may help surgeons understand the disorder and determine the appropriate treatment for patients.

We determined (1) the prevalence of radiographic coxa profunda in hip dysplasia; (2) the morphologic differences of the acetabulum and pelvis between patients with hip dysplasia and control subjects; and (3) the morphologic differences between hip dysplasia with and without coxa profunda.

\section{Patients and Methods}

This is a retrospective case-control study comparing the morphologic indices measured on pelvic CT scans for patients with dysplastic hips and control subjects, and for patients with dysplastic hips with and without coxa profunda. The institutional review board approved this study.

We reviewed the standard AP pelvic radiographs [8] and pelvic CT scans of 72 consecutive patients ( 78 hips) with symptomatic hip dysplasia obtained during their preoperative examinations for a pelvic osteotomy between June 2008 and February 2014. Inclusion criterion for this study was patients with hip dysplasia, defined as a lateral centeredge angle of Wiberg [33] less than $20^{\circ}$ on AP pelvic radiographs, and all patients met the criterion. In six patients who underwent bilateral osteotomy, the first surgically treated side was included. Exclusion criteria included prior hip surgery, advanced osteoarthritis of Grade 2 or greater according to the Tönnis classification system [32], other hip disease, or severe morphologic abnormalities of the femoral head. Two hips in two patients were scored as Tönnis Grade 2 and were excluded from this study.
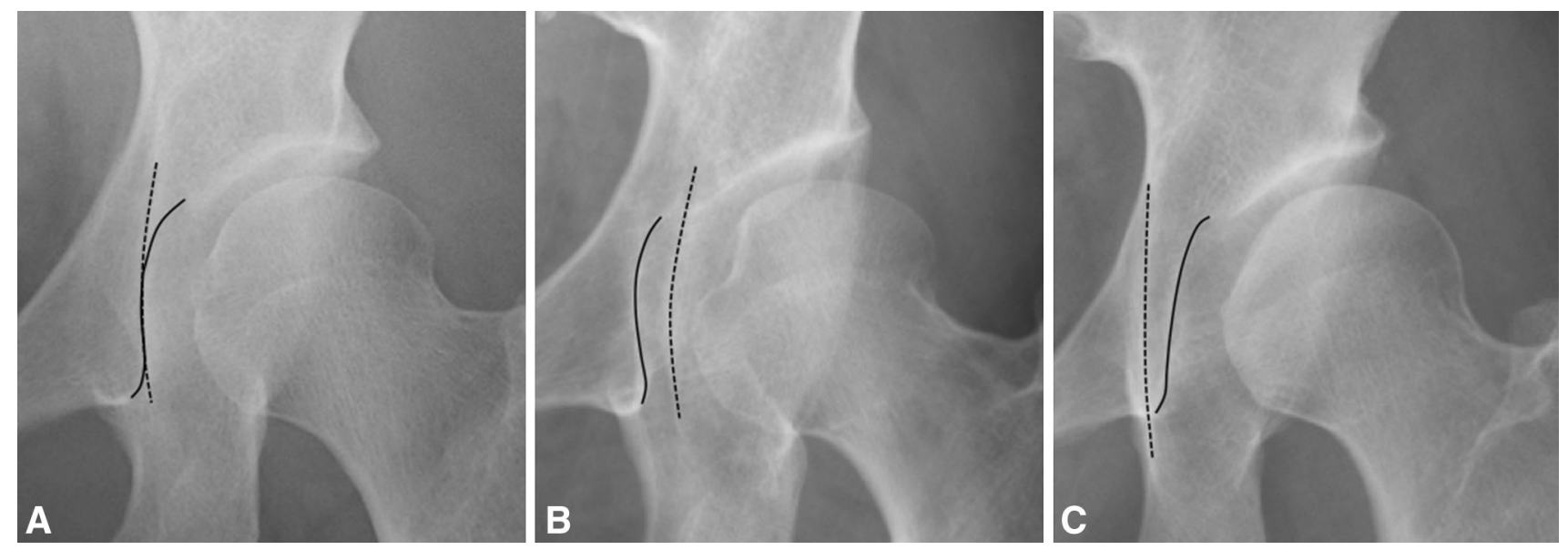

Fig. 1A-C The coxa profunda was defined as positive when the acetabular fossa (solid line) (A) touched or was (B) medial to the ilioischial line (dotted line) on an AP pelvic radiograph. (C) The coxa profunda was defined as negative when the acetabular fossa (solid line) was lateral to the ilioischial line (dotted line). 
According to these criteria, 70 patients (70 hips) were eligible for this study. There were 67 women and three men with a mean age of 46 years (SD 9.8) (Table 1). All hips were classified as Type I according to the classification system of Crowe et al. [10]. Fifty-eight patients had bilateral dysplasia and 12 had unilateral dysplasia. Although the contralateral hips of 51 patients with bilateral dysplasia were eligible for this study, these hips were not included in this study to fulfill the statistical assumption of independent observation. Only the presence of radiographic coxa profunda in these 51 contralateral hips was evaluated to determine the bilaterality of coxa profunda.

For the control subjects, we reviewed AP pelvic radiographs and CT scans of 129 patients (129 hips) with contralateral proximal femoral fractures obtained during preoperative examinations for internal fixation or hip arthroplasty between April 2012 and February 2014. Inclusion criteria for this study were patient younger than 80 years with normal hips, defined as those with a lateral center-edge angle between $25^{\circ}$ and $40^{\circ}$. Sixty patients (60 hips) met these criteria. Exclusion criteria included treatment history of hip disease, articular symptom in the hip, and degenerative changes or other hip abnormalities observed on radiographic examination. Twenty patients (20 hips) had degenerative change in the hip and were excluded from this study. According to these criteria, 40 patients with 40 normal hips were used as control subjects. There were 38 women and two men with a mean age of 68 years (SD 8.4) (Table 1). These patients had older average age and lower average BMI compared with the patients with hip dysplasia (Table 1). However, we confirmed that these patients had hips with no osteoarthritis or other abnormalities and deemed them suitable as control subjects for morphologic evaluation.

\section{Radiographic Evaluations}

Coxa profunda was defined as present when the acetabular fossa was observed to touch or was medial to the ilioischial line on a standard AP pelvic radiograph (Fig. 1) [8, 28]. Radiographic indices of the acetabular dysplasia, including the lateral center-edge angle, the Sharp angle [29], the acetabular roof obliquity [24], the head extrusion index [20], and the acetabular depth ratio [9], were measured.

\section{CT Evaluations}

Pelvic CT was performed with the patients in a supine position, and images were obtained from the superior rim to the distal femur at $1.0-\mathrm{mm}$ intervals. We performed the following measurements on the multiplanar reconstruction images using image-processing software (3-D template; Kyocera Medical Corporation, Osaka, Japan). All measurements were performed after setting the pelvic position as follows [23]: The pelvic position was aligned to the line connecting the inferior aspects of the bilateral teardrops in the coronal plane, to the line connecting the pubic symphysis and the center of the sacrum in the axial plane, and to the line connecting the anterosuperior iliac spine and the pubic tubercle in the sagittal plane.

We determined the acetabular anteversion angle in the axial plane passing through the femoral head center and the

Table 1. Comparison of the demographic and radiographic parameters between control and hip dysplasia groups

\begin{tabular}{|c|c|c|c|}
\hline Parameters & Control ( $\mathrm{n}=40$ hips) & Hip dysplasia ( $\mathrm{n}=70$ hips) & $\mathrm{p}$ value \\
\hline \multicolumn{4}{|l|}{ Demographic parameters } \\
\hline Age* (years) & $68(8.4 ; 46-79)$ & $46(9.8 ; 23-63)$ & $<0.001$ \\
\hline Gender (male:female) & 2: 38 & 3: 67 & 1.000 \\
\hline $\mathrm{BMI}^{*}\left(\mathrm{~kg} / \mathrm{m}^{2}\right)$ & $22(3.1 ; 15-29)$ & $24(3.6 ; 18-37)$ & $<0.001$ \\
\hline Laterality (left:right) & 19: 21 & $31: 39$ & 0.745 \\
\hline \multicolumn{4}{|l|}{ Radiographic parameters } \\
\hline Lateral center-edge angle* $\left(^{\circ}\right)$ & $31(3.4 ; 25-39)$ & $8.6(6.8 ;-6.1$ to 19$)$ & $<0.001$ \\
\hline Acetabular roof obliquity* $\left({ }^{\circ}\right)$ & $6.3(2.9 ; 1.0-14)$ & $23(6.1 ; 11-38)$ & $<0.001$ \\
\hline Sharp angle* $\left(^{\circ}\right)$ & $40(2.8 ; 32-46)$ & $48(3.8 ; 35-59)$ & $<0.001$ \\
\hline Head extrusion index* $(\%)$ & $15(5.0 ; 2.0-25)$ & $36(7.3 ; 18-54)$ & $<0.001$ \\
\hline Acetabular depth ratio* $(\%)$ & $262(23 ; 212-312)$ & $186(27 ; 112-229)$ & $<0.001$ \\
\hline \multicolumn{4}{|l|}{ Coxa profundal } \\
\hline Touch or medial & $29(73 \%)$ & $31(44 \%)$ & 0.004 \\
\hline Touch & $17(43 \%)$ & $23(33 \%)$ & 0.312 \\
\hline Medial & $12(30 \%)$ & $8(11 \%)$ & 0.015 \\
\hline
\end{tabular}

* Values are presented as mean (SD; range). 
Fig. 2A-B (A) The acetabular anteversion angle (AcAV) was determined in the axial plane passing through the femoral head center as the angle created by the intersection of a line connecting the anterior and posterior acetabular edges and a sagittal line. (B) The acetabular inclination angle (AI) was determined in the coronal plane passing through the femoral head center as the angle created by the intersection by a line connecting the superior and inferior acetabular edges and a horizontal line.

Fig. 3A-B The acetabular sector angle (ASA) is formed by the intersection of a line connecting the femoral head center and the acetabular edge with a horizontal line. (A) The anterior and posterior ASA were determined in the acetabular sector angle was measured in axial plane passing through the femoral head center, and the sum of the anterior and posterior ASA was defined as the axial ASA. (B) Superior ASA was measured in the coronal plane passing through the femoral head center.

Fig. 4A-B The acetabular depth ratios (ADR) were measured in the following manner: (A) the coronal ADR was determined as the ratio of acetabular depth (a) to width (b) multiplied by 1000 in the coronal plane passing through the femoral head center; (B) the axial ADR was determined as the ratio of acetabular depth (c) to width (d) multiplied by 1000 in the axial plane passing through the femoral head center.
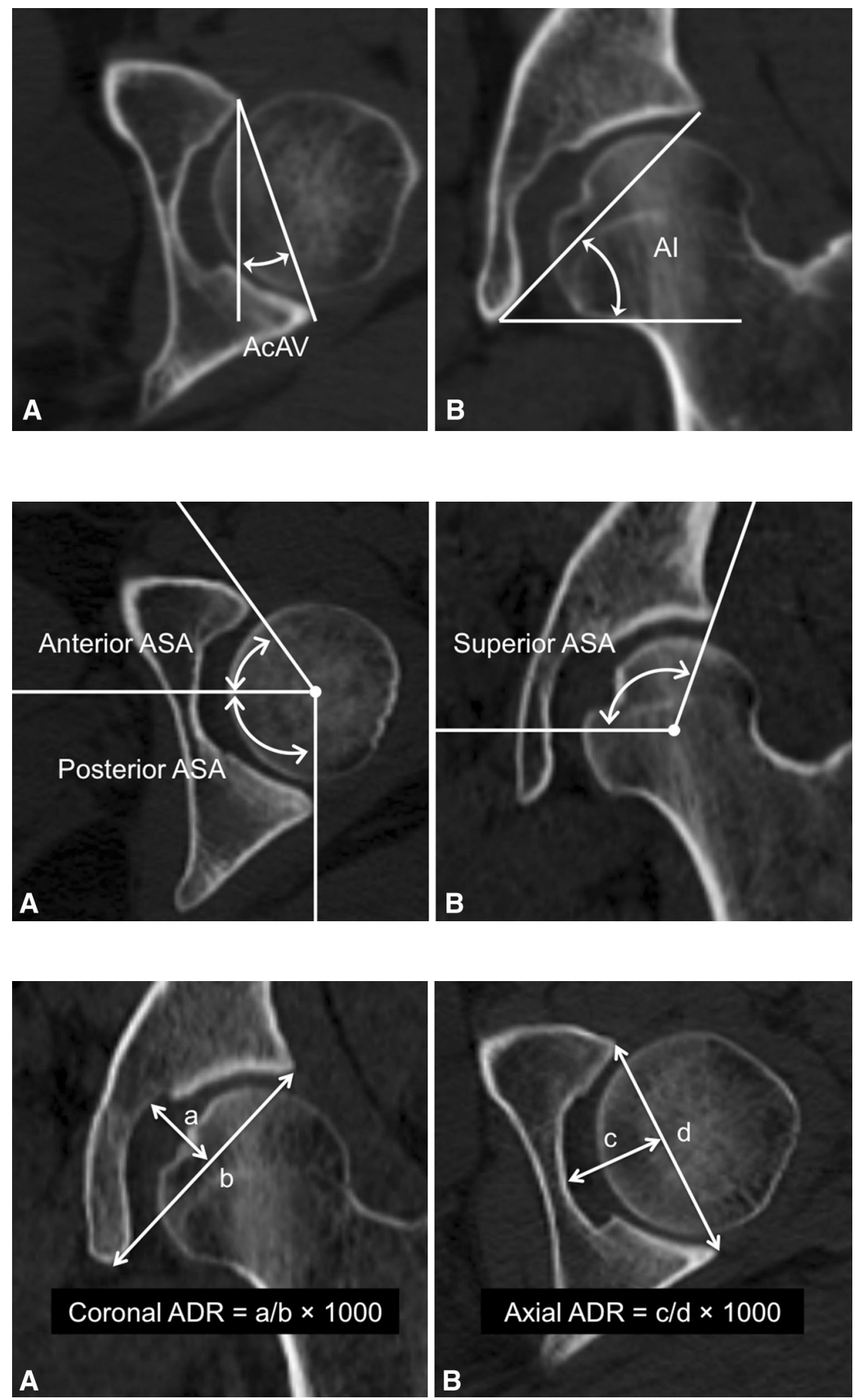

acetabular inclination angle in the coronal plane passing through the femoral head center (Fig. 2). We measured the cranial anteversion angle on the axial section $5 \mathrm{~mm}$ distal to the acetabular roof and defined the acetabular retroversion as hips with a negative cranial anteversion angle value [21]. We measured the acetabular sector angle as an indicator of the acetabular coverage of the femoral head based on the method described by Anda et al. [2] 


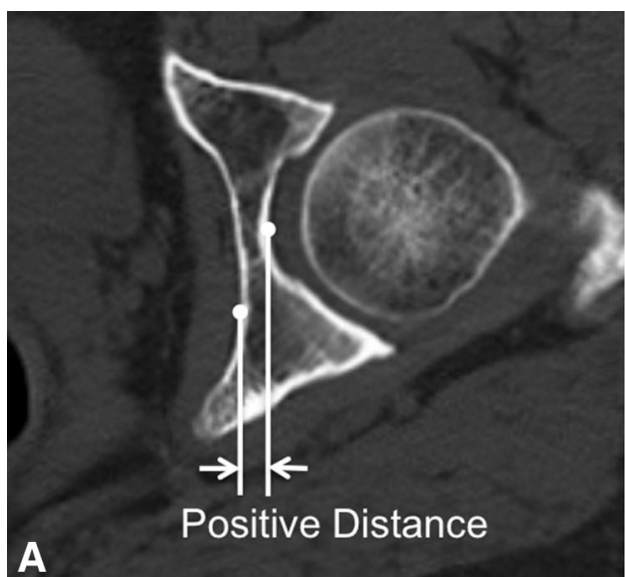

Fig. 5A-B We measured the horizontal distance between the most medial aspect of the acetabular floor and the most lateral point of the medial wall of the ischium (acetabular floor to ischial wall distance) in the axial plane passing through the femoral head center as an index of the relative position of the acetabular fossa and the ilioischial line.

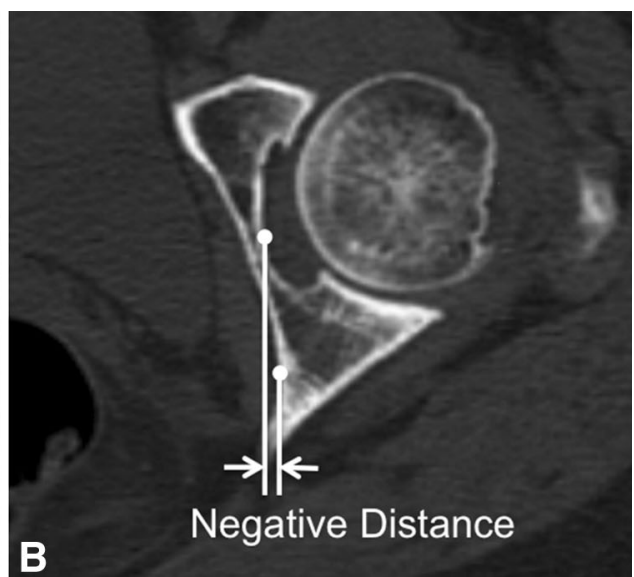

Acetabular floor to ischial wall distance was expressed as (A) positive when the acetabular floor positioned lateral to the medial wall of the ischium and (B) negative when the acetabular floor positioned medial to the medial wall of the ischium.
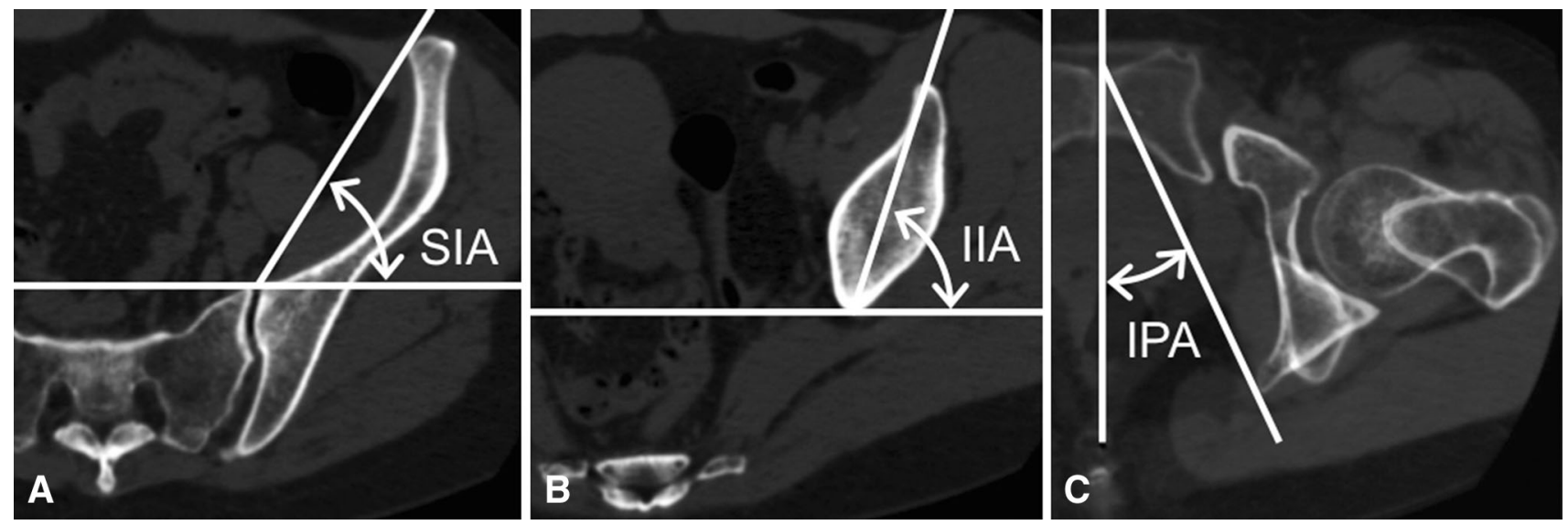

Fig. 6A-C The innominate rotation angles are shown. (A) The superior iliac wing angle (SIA) is formed by the intersection of a line connecting the medial edge of the anterosuperior iliac spine and the anterior margin of the sacroiliac joint and a horizontal line on the axial plane. (B) The inferior iliac wing angle (IIA) is formed by a line

(Fig. 3). We determined the acetabular sector angles in anterior, superior, and posterior directions [13]. The axial acetabular sector angle was defined as the sum of the anterior and posterior acetabular sector angles. To evaluate the acetabular depth, we modified the radiographic acetabular depth ratio for the CT measurement and determined the acetabular depth ratios in the axial and coronal planes (Fig. 4). We measured the horizontal distance between the most medial aspect of the acetabular floor and the most lateral point of the medial wall of the ischium (acetabular floor to ischial wall distance) as an index of the relative position of the floor of the acetabular fossa and the ilioischial line (Fig. 5). connecting the anterior aspect of the anteroinferior iliac spine and the posterior aspect of the ilium and a horizontal line on the axial plane. (C) The ischiopubic angle (IPA) is a projection angle formed by the intersection of a line connecting the anterosuperior edge of the pubic symphysis and the ischial spine and a sagittal line on the axial plane.

To evaluate the morphologic features of the pelvis, we measured the innominate rotation angles at three levels on the axial plane [13] (Fig. 6): the superior iliac angle, the inferior iliac angle, and the ischiopubic angle. The greater value of these angles indicated increased inward rotation of the pelvis.

\section{Statistical Analysis}

All the measurements were performed by the first author (MF) and were repeated in a blinded manner during two sessions at least 2 weeks apart. Intraobserver reliabilities of 
CT measurements, evaluated with use of intraclass correlation coefficient, were excellent (range, 0.94-0.99). Two independent observers ( $\mathrm{MF}$ and $\mathrm{TN}$ ) assessed all hips for the presence of the coxa profunda in a blinded manner during two sessions at least 2 weeks apart, and intra- and interobserver reliabilities were evaluated. The kappa values for intraobserver reliability were 0.82 for the first observer and 0.87 for the second observer and those for interobserver reliability were 0.87 and 0.82 for the first and second sessions, suggesting almost perfect agreement.

Student's t-tests, Welch's t-tests, or Wilcoxon rank sum tests were used to compare the continuous parameters between the two groups, depending on data distribution (Shapiro-Wilk W test and F-test). A chi-square test or Fisher's exact test was used to compare the categorical parameters as appropriate. Correlations between two continuous parameters were evaluated using Pearson's correlation coefficients. The significance level was set at a probability less than 0.05 for all tests. Statistical analyses were performed using JMP ${ }^{\circledR}$ Version 9.0 (SAS Institute Inc, Cary, NC, USA).

\section{Results}

Coxa profunda was observed in $44 \%$ (31 of 70 hips) of patients with dysplasia; the acetabular fossa touched the ilioischial line in $33 \%$ (23 of 70 hips) and was medial to the ilioischial line in $11 \%$ (eight of 70 hips) (Table 1). Coxa profunda was observed in $45 \%$ (30 of 67 hips) of women and in one of three hips of men. Of the 51 patients with bilateral hip dysplasia, 63\% (33 of 51 hips) had coxa profunda in at least one hip, and 35\% (19 of 51 hips) had bilateral coxa profunda. The prevalence of coxa profunda was $73 \%$ (29 of 40 hips) in the control subjects and was increased compared with patients with hip dysplasia ( $\mathrm{p}=$ 0.004). Coxa profunda was observed in $76 \%$ (29 of 38 hips) of women and in none of two hips of men in the control group. Neither patients' age nor BMI correlated with the presence of coxa profunda in either group.

Hips in patients with dysplasia were more anteverted and had more lateral opening (acetabular inclination) than did hips in the control subjects, whereas the groups did not differ in terms of cranial anteversion (Table 2). The prevalence of acetabular retroversion did not differ $(\mathrm{p}=0.566)$ between the patients with hip dysplasia $(16 \% ; 11$ of 70 hips) and control subjects (10\%; four of 40 hips). All the mean acetabular sector angles and acetabular depth ratios were lower in patients with hip dysplasia compared with the control subjects. Although the innominate rotation angles varied widely, the mean values were increased in patients with hip dysplasia over those of the control subjects at all three levels (Table 2).

Dysplastic hips with and without coxa profunda did not differ in terms of the demographic parameters (Table 3). The radiographic indices of the acetabular dysplasia did not differ between the two (Table 3), suggesting no correlation between the severity of the acetabular dysplasia and the presence of coxa profunda. The dysplastic hips with coxa profunda were more anteverted compared with those

Table 2. Comparison of the CT measurement values between control and hip dysplasia groups

\begin{tabular}{|c|c|c|c|}
\hline Parameters & Control ( $\mathrm{n}=40$ hips) & Hip dysplasia ( $\mathrm{n}=70$ hips) & $\mathrm{p}$ value \\
\hline \multicolumn{4}{|l|}{ Acetabular opening angle } \\
\hline Acetabular anteversion angle $\left(^{\circ}\right)$ & $21(6.7 ; 11-37)$ & $25(5.5 ; 10-37)$ & $<0.014$ \\
\hline Acetabular inclination angle $\left(^{\circ}\right)$ & $39(3.2 ; 33-46)$ & $49(3.8 ; 38-61)$ & $<0.001$ \\
\hline Cranial anteversion angle $\left({ }^{\circ}\right)$ & $12(8.6 ;-8.4$ to 27$)$ & $11(8.8 ;-6.8$ to 31$)$ & 0.537 \\
\hline \multicolumn{4}{|l|}{ Acetabular coverage } \\
\hline Anterior acetabular sector angle $\left(^{\circ}\right)$ & $57(9.4 ; 38-74)$ & $42(6.9 ; 27-55)$ & $<0.001$ \\
\hline Superior acetabular sector angle $\left(^{\circ}\right)$ & $123(4.6 ; 115-133)$ & $99(6.9 ; 87-114)$ & $<0.001$ \\
\hline Posterior acetabular sector angle $\left(^{\circ}\right)$ & $99(7 ; 80-112)$ & $91(6.8 ; 71-107)$ & $<0.001$ \\
\hline Axial acetabular sector angle $\left(^{\circ}\right)$ & $156(9.9 ; 137-176)$ & $133(8.5 ; 112-153)$ & $<0.001$ \\
\hline \multicolumn{4}{|l|}{ Acetabular depth } \\
\hline Coronal acetabular depth ratio (\%) & $300(29 ; 243-361)$ & $226(40 ; 140-317)$ & $<0.001$ \\
\hline Axial acetabular depth ratio (\%) & $441(32 ; 378-519)$ & $404(39 ; 296-492)$ & $<0.001$ \\
\hline Innominate rotation angles & & & $<0.001$ \\
\hline Superior iliac angle $\left(^{\circ}\right)$ & $52(6.5 ; 39-679)$ & $58(6.1 ; 45-68)$ & $<0.001$ \\
\hline Inferior iliac angle $\left(^{\circ}\right)$ & $70(5.2 ; 61-82)$ & $71(4.1 ; 62-82)$ & 0.028 \\
\hline Ischiopubic angle $\left(^{\circ}\right)$ & $28(2.7 ; 22-34)$ & $30(2.8 ; 22-39)$ & $<0.001$ \\
\hline Acetabular floor to ischial wall distance $(\mathrm{mm})$ & $0.6(3.0 ;-5.1$ to 5.9$)$ & $0.6(2.4 ;-5.0$ to 5.6$)$ & 0.917 \\
\hline
\end{tabular}

Values are presented as mean (SD; range). 
without coxa profunda (Table 4). The prevalence of acetabular retroversion was lower $(p<0.001)$ in hips with coxa profunda (none of 31 hips) than in those without coxa profunda (28\%; 11 of 39 hips). Regarding acetabular coverage, the hips with coxa profunda had a smaller anterior acetabular sector angle and a larger posterior acetabular sector angle compared with those without coxa profunda (Table 4). There was no difference in the superior and axial acetabular sector angles. The coronal and axial acetabular depth ratio did not differ between the two groups, with the numbers available (Table 4). Regarding morphologic features of the pelvis, hips with coxa profunda had greater innominate rotation angles compared with those without coxa profunda at all three levels (Table 4), suggesting a more inwardly rotated pelvis in coxa profunda hips. The dysplastic hips with coxa profunda had lower acetabular floor to ischial wall distance compared with those without coxa profunda (Table 4). Acetabular floor to ischial wall distance was correlated with acetabular anteversion, cranial anteversion, and the innominate rotation angles (especially with the inferior iliac angle and ischiopubic angle) in patients with hip dysplasia and the control subjects (Table 5). This indicates increased acetabular anteversion and inward rotation of the innominate bone, shifting the floor of the acetabular fossa medially relative to the ilioischial line. The acetabular sector angles and

Table 3. Comparison of the demographic and radiographic parameters between hips with and without coxa profunda in hip dysplasia

\begin{tabular}{llll}
\hline Parameters & $\begin{array}{l}\text { Coxa profunda }(-) \\
(\mathrm{n}=39 \text { hips })\end{array}$ & $\begin{array}{l}\text { Coxa profunda }(+) \\
(\mathrm{n}=31 \text { hips })\end{array}$ \\
\hline $\begin{array}{l}\text { Demographic parameters } \\
\text { Age* (years) }\end{array}$ & $46(11 ; 23-62)$ & $46(8.6 ; 28-63)$ \\
Gender (male:female) & $2: 37$ & $1: 30$ & 0.924 \\
Body mass index* $\left(\mathrm{kg} / \mathrm{m}^{2}\right)$ & $24(3.9 ; 18-37)$ & $24(3.4 ; 19-34)$ & $16: 15$ \\
Laterality (left:right) & $15: 24$ & & 0.696 \\
Radiographic parameters & $9.1(7.0 ;-6.1$ to 19$)$ & $24(6.2 ; 11-38)$ & 0.966 \\
Lateral center-edge angle* $\left(^{\circ}\right)$ & $22(6.0 ; 12-37)$ & $49(4.2 ; 35-59)$ & $37(6.8 ; 26-54)$ \\
Acetabular roof obliquity* $\left(^{\circ}\right)$ & $47(3.5 ; 41-57)$ & $184(27 ; 125-227)$ \\
Sharp angle* $\left({ }^{\circ}\right)$ & $36(7.7 ; 18-50)$ & & 0.369 \\
Head extrusion index* $(\%)$ & $187(28 ; 112-229)$ & 0.240 \\
Acetabular depth ratio* $(\%)$ & & 0.132 \\
\hline
\end{tabular}

* Values are presented as mean (SD; range).

Table 4. Comparison of the CT measurement values between hips with and without coxa profunda in hip dysplasia

\begin{tabular}{|c|c|c|c|}
\hline Parameters & Coxa profunda $(-)(\mathrm{n}=39$ hips $)$ & Coxa profunda $(+)(\mathrm{n}=31 \mathrm{hips})$ & $\mathrm{p}$ value \\
\hline \multicolumn{4}{|l|}{ Acetabular opening angle } \\
\hline Acetabular anteversion angle $\left(^{\circ}\right)$ & $22(4.7 ; 10-32)$ & $28(4.1 ; 20-37)$ & $<0.001$ \\
\hline Acetabular inclination angle $\left(^{\circ}\right)$ & $48(3.3 ; 42-56)$ & $49(4.3 ; 38-61)$ & 0.180 \\
\hline Cranial anteversion angle $\left(^{\circ}\right)$ & $7.2(7.6 ;-6.8$ to 21$)$ & $16(1.4 ; 2.2-31)$ & $<0.001$ \\
\hline \multicolumn{4}{|l|}{ Acetabular coverage } \\
\hline Anterior acetabular sector angle $\left(^{\circ}\right)$ & $44(6.6 ; 28-55)$ & $39(5.9 ; 27-52)$ & $<0.001$ \\
\hline Superior acetabular sector angle $\left(^{\circ}\right)$ & $100(6.8 ; 87-111)$ & $99(7.0 ; 87-114)$ & 0.173 \\
\hline Posterior acetabular sector angle $\left(^{\circ}\right)$ & $89(6.1 ; 71-100)$ & $94(6.2 ; 77-107)$ & $<0.001$ \\
\hline Axial acetabular sector angle $\left(^{\circ}\right)$ & $133(8.3 ; 116-147)$ & $133(8.8 ; 112-153)$ & 0.951 \\
\hline \multicolumn{4}{|l|}{ Acetabular depth } \\
\hline Coronal acetabular depth ratio $(\%)$ & $231(37 ; 148-317)$ & $219(43 ; 140-297)$ & 0.207 \\
\hline Axial acetabular depth ratio (\%) & $396(41 ; 296-460)$ & $414(34 ; 325-492)$ & 0.061 \\
\hline \multicolumn{4}{|l|}{ Innominate rotation angles } \\
\hline Superior iliac angle $\left(^{\circ}\right)$ & $56(6.1 ; 45-65)$ & $60(5.1 ; 50-68)$ & 0.002 \\
\hline Inferior iliac angle $\left(^{\circ}\right)$ & $69(4.0 ; 62-79)$ & $74(3.1 ; 67-82)$ & $<0.001$ \\
\hline Ischiopubic angle $\left(^{\circ}\right)$ & $29(2.3 ; 22-33)$ & $31(2.9 ; 25-39)$ & $<0.001$ \\
\hline Acetabular floor to ischial wall distance (mm) & $2.0(1.8 ;-2.2$ to 5.6$)$ & $-1.3(1.5 ;-5.0$ to 1.3$)$ & $<0.001$ \\
\hline
\end{tabular}

Values are presented as mean (SD; range). 
Table 5. Correlation between acetabular floor to ischial wall distance and CT measurement values

\begin{tabular}{|c|c|c|}
\hline Parameters & $\begin{array}{l}\text { Control ( } \mathrm{n}=40 \text { hips }) \\
\text { Acetabular floor to ischial wall distance }\end{array}$ & $\begin{array}{l}\text { Hip dysplasia ( } \mathrm{n}=70 \text { hips) } \\
\text { Acetabular floor to ischial wall distance }\end{array}$ \\
\hline \multicolumn{3}{|l|}{ Acetabular opening angle } \\
\hline Acetabular anteversion angle $\left(^{\circ}\right)$ & $-0.571(-0.750$ to $-0.316 ;<0.001)$ & $-0.686(-0.794$ to $-0.537 ;<0.001)$ \\
\hline Cranial anteversion angle $\left(^{\circ}\right)$ & $-0.525(-0.719$ to $-0.255 ;<0.001)$ & $-0.534(-0.684$ to $-0.340 ;<0.001)$ \\
\hline \multicolumn{3}{|l|}{ Acetabular coverage } \\
\hline Superior acetabular sector angle $\left(^{\circ}\right)$ & $0.239(-0.078$ to $0.513 ; 0.137)$ & $-0.025(-0.260$ to $0.2127 ; 0.837)$ \\
\hline Axial acetabular sector angle $\left({ }^{\circ}\right)$ & $-0.072(-0.375$ to $0.245 ; 0.658)$ & $-0.176(-0.396$ to $0.064 ; 0.149)$ \\
\hline \multicolumn{3}{|l|}{ Acetabular depth } \\
\hline Coronal acetabular depth ratio (\%) & $-0.084(-0.386$ to $0.233 ; 0.605)$ & $0.007(-0.230$ to $0.243 ; 0.956)$ \\
\hline Axial acetabular depth ratio $(\%)$ & $-0.102(-0.401$ to $0.217 ; 0.532)$ & $-0.274(-0.480$ to $-0.040 ; 0.023)$ \\
\hline \multicolumn{3}{|l|}{ Innominate rotation angles } \\
\hline Superior iliac angle $\left({ }^{\circ}\right)$ & $-0.433(-0.656$ to $-0.141 ; 0.005)$ & $-0.287(-0.491$ to $-0.054 ; 0.017)$ \\
\hline Inferior iliac angle $\left(^{\circ}\right)$ & $-0.669(-0.811$ to $-0.452 ;<0.001)$ & $-0.570(-0.711$ to $-0.386 ;<0.001)$ \\
\hline Ischiopubic angle $\left(^{\circ}\right)$ & $-0.639(-0.793$ to $-0.409 ;<0.001)$ & $-0.602(-0.734$ to $-0.426 ;<0.001)$ \\
\hline
\end{tabular}

Values are presented as correlation coefficients (95\% CI; $\mathrm{p}$ value).

acetabular depth ratios had no important correlation with acetabular floor to ischial wall distance in patients with hip dysplasia and the control subjects (Table 5).

\section{Discussion}

Although radiographic coxa profunda has been considered an indicator of acetabular overcoverage or pincer FAI, previous studies suggested that coxa profunda is a nonspecific finding seen in asymptomatic hips and hips with various hip diseases, including hip dysplasia [3, 6, 27]. To date, the morphologic features and clinical importance of coxa profunda in hip dysplasia are not well characterized. In this study, we observed coxa profunda in $44 \%$ of dysplastic hips. Dysplastic hips had a more anteverted acetabulum with inwardly rotated pelvis compared with hips in the control subjects. The increased anteversion of the acetabulum and inward rotation of the pelvis were correlated with the presence of coxa profunda in patients with hip dysplasia, whereas the acetabular coverage and depth had no correlation with the presence of coxa profunda.

This study has several limitations. First, the control subjects were older than the patients with hip dysplasia. Although we recognize that subjects with the same age range would be ideal for control, it is generally difficult to obtain qualified CT images of asymptomatic normal hips in the young adult population. In this study, we confirmed that control subjects had no history of hip disease, osteoarthritis, or other hip abnormalities, and deemed them suitable as control subjects for morphologic evaluation. Additionally, we confirmed no correlation between patients' age and the presence of coxa profunda. Thus, we assume the age difference has little effect on the study results. Second, patients with hip dysplasia evaluated in this study were symptomatic and were undergoing surgery, therefore this was a group composed of patients with more severe dysplasia. This raises concern that our observation may apply only to this population with more severe dysplastic hips. Although we excluded the contralateral hips of 51 patients with bilateral dysplasia, similar results were found in these contralateral hips including asymptomatic mild dysplasia. Thus, we assume that our observations apply to all degrees of dysplastic hips. Third, the study cohort was limited to Asian patients. Previous studies have shown differences in morphologic features of the hip between Asians and whites [12, 34]: Asians have a shallower acetabulum compared with whites. We believe that our observations may not be affected by the racial difference and are generalizable to whites and all Asian patients; however, further investigation is needed to address the effect of racial differences on the generalizability of our observations. Fourth, all measurements using CT images were performed by one observer (MF); this raises the concern for assessment bias. However, intra- and interobserver reliabilities of measurements on multiplanar reconstructed images has been validated in previous studies $[13,14]$ and we assume the effect of assessment bias on the study results is negligible.

The coxa profunda was observed in $44 \%$ ( 31 of 70 hips) of dysplastic hips in this study, and the prevalence was comparable to that previously reported. Nepple et al. [27] reported $41 \%$ ( 24 of $58 \mathrm{hips}$ ) of patients with symptomatic acetabular dysplasia had coxa profunda. Anderson et al. [3] reported 58\% (43 of 74 hips) of patients who underwent periacetabular osteotomy had coxa profunda, $88 \%$ of 
whom had deficient coverage. A considerable prevalence $(44 \%)$ of dysplastic hips with coxa profunda suggests an underlying morphologic factor other than acetabular coverage or depth that contributes to the presence of coxa profunda, such as acetabular anteversion [31]. The prevalence of coxa profunda in normal hips was $73 \%$ (29 of 40 hips) in our study. Previous studies have shown a high prevalence of coxa profunda in normal asymptomatic hips, especially in females [4, 27]. Armbuster et al. [4] reported that the acetabular line was superimposed on or was medial to the ilioischial line (currently defined as coxa profunda) in $83 \%$ (68 of 82 hips) of female hips and $28 \%$ (71 of 232 hips) of male hips. Nepple et al. [27] reported $76 \%$ (25 of 33 hips) of asymptomatic normal hips had coxa profunda (88\% of females and $44 \%$ of males). Anderson et al. [3] reported the coxa profunda was seen in 34\% (45 of 134 hips) of asymptomatic male hips, and $91 \%$ of the hips with coxa profunda had normal or deficient acetabular coverage. Coxa profunda was more common in normal hips compared with dysplastic hips; indicating that increased acetabular coverage and depth may contribute to the presence of coxa profunda. However, the results of our study and previous studies indicated that coxa profunda is poorly specific for acetabular overcoverage or pincer-type FAI. We agree with the suggestion of previous studies that coxa profunda is one of the normal radiographic findings, at least in females [3, 6, 27].

Dysplastic hips had a more anteverted and globally shallow acetabulum compared with the control hips in our study. Although rotational alignment of the innominate bone varied widely among individuals, the mean value showed the innominate bone was substantially inwardly rotated in patients with hip dysplasia compared with the control subjects, especially at the superior ilium level.
Numerous morphologic abnormalities associated with hip dysplasia have been reported, including increased acetabular anteversion and inclination, globally deficient acetabular coverage of the femoral head, and shallow acetabular concavity [11, 14, 25]. Our observation was comparable to these studies. It was reported that a principal pelvic deformity in hip dysplasia is an inwardly rotated innominate bone with an iliac wing that opens inwardly relative to the ischiopubis, and the morphologic features of the entire pelvis were correlated with morphologic features of the acetabulum [13]. Our observations support the suggestion of the study by Fujii et al. [13] that the structural abnormalities exist throughout the pelvis in patients with hip dysplasia.

The results of our study showed that hips with increased acetabular anteversion and an inwardly rotated pelvis tended to have coxa profunda, regardless of the degree of acetabular coverage and depth, in patients with hip dysplasia and control subjects. To our knowledge, there have been no reports that showed the morphologic correlation of coxa profunda with acetabular anteversion and inward rotation of the pelvis. Radiographic coxa profunda is determined by the relative position of the floor of the acetabular fossa and the ilioischial line [8, 28], and the relationship of these projection lines should be affected by various morphologic characteristics other than acetabular coverage or depth. Inward rotation of the innominate bone was reported to be associated with increased acetabular anteversion [13]. The inward rotation of the innominate bone, especially in the distal ilium to the ischiopubic portion, should be a potent morphologic factor that makes the acetabulum more anteverted and shifts the floor of the acetabular fossa medially relative to the ilioischial line, resulting in the presence of the coxa profunda (Fig. 7).
Fig. 7A-B (A) A dysplastic hip with excessively anteverted acetabulum and inwardly rotated pelvis tends to have coxa profunda. (B) In contrast, a dysplastic hip with a less anteverted acetabulum and outwardly rotated pelvis does not have coxa profunda.
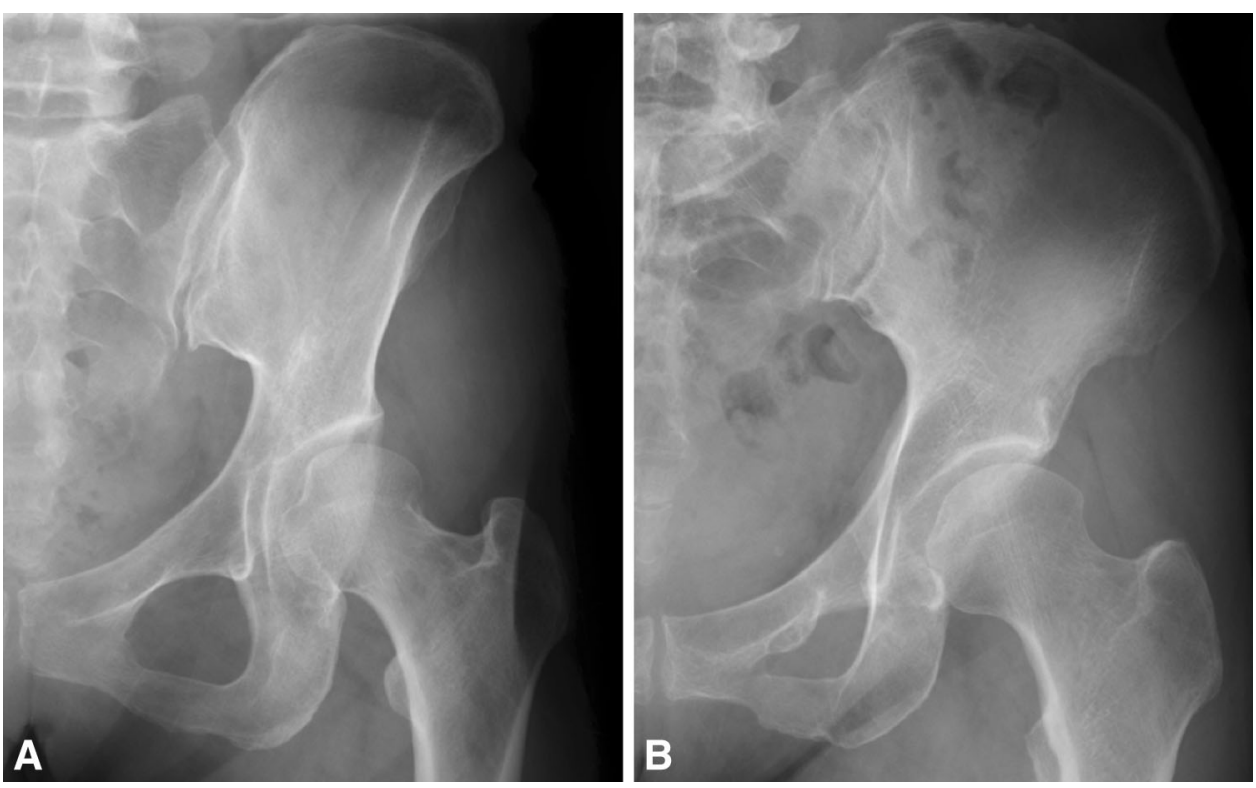
Based on these observations, we conclude that coxa profunda is not useful in diagnosing pincer-type FAI. The morphologic features of hip dysplasia, that is, an inwardly rotated pelvis and excessively anteverted acetabulum, may be a potent morphologic factor for the high prevalence (44\%) of coxa profunda in patients with hip dysplasia. Coxa profunda indicates classic acetabular dysplasia, defined by an anteverted acetabulum with deficiency in anterolateral acetabular coverage of the femoral head and an inwardly rotated pelvis. Thus, the conventional corrective maneuvers during periacetabular osteotomy, that is, lateral rotation, forward tilt, and medial translation [7] of the acetabular fragment, are adequate for these patients.

Results of our study showed the presence of the radiographic coxa profunda is not a sign of increased acetabular coverage or depth in patients with hip dysplasia but indicates classic acetabular dysplasia, defined by an anteverted acetabulum with deficiency in anterolateral acetabular coverage of the femoral head and an inwardly rotated pelvis. Therefore we assume the presence of the coxa profunda does not indicate disease in addition to hip dysplasia, and the conventional corrective maneuvers during periacetabular osteotomy, that is, lateral rotation, forward tilt, and medial translation [7] of the acetabular fragment, are adequate for these patients.

Acknowledgments We thank Kuniyoshi Tsuchiya MD, PhD, Hidetoshi Yano MD, Tatsuya Nishijima MD, Kosei Miyazaki MD, Kei Kurose MD (Department of Orthopaedic Surgery, JCHO Kyushu Hospital, Kitakyushu, Japan) for their invaluable advice for this study.

\section{References}

1. Albers CE, Steppacher SD, Ganz R, Tannast M, Siebenrock KA. Impingement adversely affects 10-year survivorship after periacetabular osteotomy for DDH. Clin Orthop Relat Res. 2013; 471:1602-1614.

2. Anda S, Svenningsen S, Dale L, Benum P. The acetabular sector angle of the adult hip determined by computed tomography. Acta Radiol Diagn (Stockh). 1986;27:443-447.

3. Anderson LA, Kapron AL, Aoki SK, Peters CL. Coxa profunda: is the deep acetabulum overcovered? Clin Orthop Relat Res. 2012;470:3375-3382.

4. Armbuster TG, Guerra J Jr, Resnick D, Goergen TG, Feingold ML, Niwayama G, Danzig LA. The adult hip: an anatomic study. Part I: the bony landmarks. Radiology. 1978;128:1-10.

5. Beck M, Kalhor M, Leunig M, Ganz R. Hip morphology influences the pattern of damage to the acetabular cartilage: femoroacetabular impingement as a cause of early osteoarthritis of the hip. $J$ Bone Joint Surg Br. 2005;87:1012-1018.

6. Boone G, Pagnotto MR, Walker JA, Trousdale RT, Sierra RJ. Radiographic features associated with differing impinging hip morphologies with special attention to coxa profunda. Clin Orthop Relat Res. 2012;470:3368-3374.

7. Clohisy JC, Barrett SE, Gordon JE, Delgado ED, Schoenecker PL. Periacetabular osteotomy in the treatment of severe acetabular dysplasia: surgical technique. J Bone Joint Surg Am. 2006; 88(suppl 1):65-83.
8. Clohisy JC, Carlisle JC, Beaulé PE, Kim YJ, Trousdale RT, Sierra RJ, Leunig M, Schoenecker PL, Millis MB. A systematic approach to the plain radiographic evaluation of the young adult hip. J Bone Joint Surg Am. 2008;90(suppl 4):47-66.

9. Cooperman DR, Wallensten R, Stulberg SD. Acetabular dysplasia in the adult. Clin Orthop Relat Res. 1983;175:79-85.

10. Crowe JF, Mani VJ, Ranawat CS. Total hip replacement in congenital dislocation and dysplasia of the hip. J Bone Joint Surg Am. 1979;61:15-23.

11. Dandachli W, Kannan V, Richards R, Shah Z, Hall-Craggs M, Witt J. Analysis of cover of the femoral head in normal and dysplastic hips: new CT-based technique. J Bone Joint Surg Br. 2008;90:1428-1434.

12. Dudda M, Kim YJ, Zhang Y, Nevitt MC, Xu L, Niu J, Goggins J, Doherty M, Felson DT. Morphologic differences between the hips of Chinese women and white women: could they account for the ethnic difference in the prevalence of hip osteoarthritis? Arthritis Rheum. 2011;63:2992-2999.

13. Fujii M, Nakashima Y, Sato T, Akiyama M, Iwamoto Y. Pelvic deformity influences acetabular version and coverage in hip dysplasia. Clin Orthop Relat Res. 2011;469:1735-1742.

14. Fujii M, Nakashima Y, Yamamoto T, Mawatari T, Motomura G, Matsushita A, Matsuda S, Jingushi S, Iwamoto Y. Acetabular retroversion in developmental dysplasia of the hip. J Bone Joint Surg Am. 2010;92:895-903.

15. Ganz R, Leunig M. Morphological variations of residual hip dysplasia in the adult. Hip Int. 2007;17(suppl 5):S22-28.

16. Ganz R, Parvizi J, Beck M, Leunig M, Nötzli H, Siebenrock KA. Femoroacetabular impingement: a cause for osteoarthritis of the hip. Clin Orthop Relat Res. 2003;417:112-120.

17. Genda E, Konishi N, Hasegawa Y, Miura T. A computer simulation study of normal and abnormal hip joint contact pressure. Arch Orthop Trauma Surg. 1995;114:202-206.

18. Harris WH. Etiology of osteoarthritis of the hip. Clin Orthop Relat Res. 1986;213:20-33.

19. Henak CR, Ellis BJ, Harris MD, Anderson AE, Peters CL, Weiss JA. Role of the acetabular labrum in load support across the hip joint. J Biomech. 2011;44:2201-2206.

20. Heyman $\mathrm{CH}$, Herndon $\mathrm{CH}$. Legg-Perthes disease; a method for the measurement of the roentgenographic result. J Bone Joint Surg Am. 1950;32:767-778.

21. Jamali AA, Mladenov K, Meyer DC, Martinez A, Beck M, Ganz $\mathrm{R}$, Leunig M. Anteroposterior pelvic radiographs to assess acetabular retroversion: high validity of the 'cross-over-sign.' $J$ Orthop Res. 2007;25:758-765.

22. Klaue K, Durnin CW, Ganz R. The acetabular rim syndrome: a clinical presentation of dysplasia of the hip. J Bone Joint Surg Br. 1991;73:423-429.

23. Lewinnek GE, Lewis JL, Tarr R, Compere CL, Zimmerman JR. Dislocations after total hip-replacement arthroplasties. J Bone Joint Surg Am. 1978;60:217-220.

24. Massie WK, Howorth MB. Congenital dislocation of the hip: Part I. Method of grading results. J Bone Joint Surg Am. 1950;32: 519-531.

25. Murphy SB, Kijewski PK, Millis MB, Harless A. Acetabular dysplasia in the adolescent and young adult. Clin Orthop Relat Res. 1990;261:214-223.

26. Myers SR, Eijer H, Ganz R. Anterior femoroacetabular impingement after periacetabular osteotomy. Clin Orthop Relat Res. 1999;363:93-99.

27. Nepple JJ, Lehmann CL, Ross JR, Schoenecker PL, Clohisy JC. Coxa profunda is not a useful radiographic parameter for diagnosing pincer-type femoroacetabular impingement. J Bone Joint Surg Am. 2013;95:417-423.

28. Ruelle M, Dubois JL. [The protrusive malformation and its arthrosic complication: I. Radiological and clinical symptoms: 
etiopathogenesis] [in French]. Rev Rhum Mal Osteoartic. 1962;29: 476-489.

29. Sharp IK. Acetabular dysplasia: the acetabular angle. $J$ Bone Joint Surg Br. 1961;43:268.

30. Siebenrock KA, Schoeniger R, Ganz R. Anterior femoro-acetabular impingement due to acetabular retroversion: treatment with periacetabular osteotomy. J Bone Joint Surg Am. 2003;85: 278-286.

31. Tannast M, Leunig M; Session Participants. Report of breakout session: coxa profunda/protrusio management. Clin Orthop Relat Res. 2012;470:3459-3461.
32. Tönnis D, Legal H, Graf R. Congenital Dysplasia and Dislocation of the Hip in Children and Adults. Berlin, Germany: SpringerVerlag; 1987:165-171.

33. Wiberg G. Studies on dysplastic acetabula and congenital subluxation of the hip joint: with special reference to the complication of osteo-arthritis. Acta Chir Scand. 1939;83(suppl 58):5-135.

34. Yoshimura N, Campbell L, Hashimoto T, Kinoshita H, Okayasu T, Wilman C, Coggon D, Croft P, Cooper C. Acetabular dysplasia and hip osteoarthritis in Britain and Japan. Br J Rheumatol. 1998;37:1193-1197. 